\title{
The Relationship of Illness Perception and Medication Adherence in Patients With Diabetes Mellitus Type II
}

\section{Sina Sabeti Bilondi}

Azad University: Islamic Azad University

Ali Delshad Noghabi ( $\square$ ali_delshad2000@yahoo.com )

Gonabad University of Medical Sciences https://orcid.org/0000-0001-9844-7967

Hosein Aalami

Gonabad University of Medical Sciences

\section{Research}

Keywords: illness perception, medication Adherence, type II diabetes

Posted Date: April 16th, 2021

DOl: https://doi.org/10.21203/rs.3.rs-426152/v1

License: (c) (i) This work is licensed under a Creative Commons Attribution 4.0 International License.

Read Full License 


\title{
The relationship of illness perception and medication adherence in patients with diabetes mellitus type II
}

\author{
Sina Sabeti Bilondi ${ }^{1}$, Ali Delshad Noghabi ${ }^{2 *}$, Hosein Aalami ${ }^{3}$
}

\begin{abstract}
Background: One of the most well-known chronic diseases in the world is diabetes. Disease perception is the patient's organized cognitive representation of his or her illness and can affect treatment adherence. The aim of this study was to investigate the relationship between illness perception and adherence to the medical regimen in patients with type II diabetes.

Methods: This descriptive-analytical cross-sectional study was performed on 260 patients with type II diabetes referred to Gonabad Diabetes Clinic by systematic random sampling in 2019. Data collection tools were demographic questionnaire, Morisky medication Adherence Scale (MMAS-8), and Brief illness Perception Questionnaire (BIPQ). Data were analyzed by SPSS 20 software. And using descriptive statistics, Pearson correlation coefficient. $\mathrm{P}<0.05$ was considered significant.

Results: The results showed that the mean score of illness perception of type II diabetes was $46.39 \pm 9.45$ (range 0-70) and the mean score of medication Adherence was $2.93 \pm 1.9$ (range 0-8). The results of Pearson correlation test showed a significant relationship between illness perception and medication Adherence $(\mathrm{P}<0.001, \mathrm{r}$ $=0.199$ ). Also, the regression model showed that the dimensions of disease comprehension and personal control from illness perception were significantly related to medication Adherence of type II diabetic patients $(\mathrm{P}<0.001)$.
\end{abstract}

Conclusion: By measuring the level of illness perception, the degree of medication Adherence can be predicted. Therefore, strengthening the illness perception in order to medication Adherence seems to be an important therapeutic strategy in educational interventions.

Keywords: illness perception, medication Adherence, type II diabetes

\footnotetext{
*Correspondence: $\underline{\text { ali_delshad2000@yahoo.com }}$

${ }^{2}$ Social Development and Health Promotion Research Center, Gonabad University of Medical Sciences, Gonabad, Iran
} 


\section{Background}

Population aging, as well as reducing the outbreak of infectious diseases by improving the medical and health care on the one hand, and the poor lifestyle, on the other hand, have increased the prevalence of chronic diseases in the world. Chronic diseases causes $70 \%$ of deaths in the United States, or 1.7 million deaths each year [1]. Diabetes is of the most well-known chronic diseases across the world [2]. According to the World Health Organization, the number of people with diabetes mellitus was 30 million in the last decade, 170 million in the current decade, and is projected to reach 366 million in 2030 [3]. According to the US National Institutes of Health (NIH), more than 18 million people $(6.3 \%)$ of the US population have diabetes [4]. The prevalence of diagnosed and undiagnosed diabetes in Iranian men is $8.1 \%$ and $5.1 \%$, respectively, and this prevalence in women is $10 \%$ and $4.7 \%$ [5]. Type II diabetes (T2DM) leads to decreased life expectancy (up to 8 years), increased cardiovascular, cerebral, peripheral vascular disease, vision problems, depression, nephropathy, and $60 \%$ of amputations [6]. The financial burden on society is increasing due to the health care cost and population aging with diabetes, so that half of diabetics over 65 years are hospitalized every year [7]. Diabetes is not curable, but it can be controlled [8]. Diabetes medication is very complex [9]. Studies have shown that patients adhere to a complex medication less than a simple one [10]. Patients' poor medication adherence is one of the major clinical concerns that health system employees often face, which has been considered by many researchers and international symposia as one of the complex and essential problems of the present age in the last two decades [11]. The World Health Organization (WHO) recommends the term adherence for use in chronic diseases. According to WHO definition, adherence means the amount of behavior performed by an individual, including medication, diet, or lifestyle changes by health care personnel's recommendations [12]. Non-adherence to medication in diabetic patients is correlated to frequent hospitalizations, non-receipt treatment benefits, high treatment costs, and many physician visits. The death rate in patients who do not adhere to their medication is twice as high as other patients [13]. Illness perception is one of the most critical factors. Illness perception refers to the patient's organized cognitive representation of his/her illness [14]. According to Leventhal's theory, patients regulate their behavior and emotional response to disease based on their perception of nature, causes, outcome, controllability, and illness duration. Bandura states that illness perception provides an essential framework for examining patients' beliefs and the impact of its components on health behaviors [15]. Illness perception includes 7 areas of identity (illness perception symptoms), course of the disease (chronic or acute), disease outcome, individual control, therapeutic control, coping with the disease, a period without disease, and emotional manifestations of the disease [16]. Various studies have supported the relationship between illness perception and medication adherence [17, 18]. Rajpura and Nayak (2014) showed that the illness perception and positive beliefs about treatment in the elderly with hypertension correlate with medication adherence [17]. Chen et al. (2011) showed that illness perception is correlated to medication adherence [19]. Illness perception has a predictive value in using the

health behaviors of patients with chronic diseases. Perceptions of the disease can vary in different socio-cultural contexts. Moreover, no study has been found on patients with T2DM and its impact on medication adherence. 


\section{Aim of the study}

the purpose of this research is to investigate the relationship between illness perception and medication adherence in patients with type II diabetes referred to the diabetes clinic of Allameh Bohlool Gonabadi Hospital (Gonabad University of Medical Sciences \& Health Services) in 2019.

\section{Methods}

\section{Design and setting of the study}

This research has employed a cross-sectional descriptive method. The research population included type II diabetes patients referred to the only specialized diabetes clinic of Allameh Bhlul Gonabadi Hospital in 2019. The sample size was obtained according to the study of Dost Mohammadi et al. [21] and based on the formula below, as many as 242 people with $95 \%$ confidence interval and $80 \%$ test power. Finally, 260 was set given about $10 \%$ of exclusion.

$$
n=\frac{\left(Z_{1-\frac{\alpha}{2}}+Z_{1-\beta}\right)^{2}}{(\omega)^{2}}+3
$$

Sampling was conducted through systematic random sampling. The inclusion criteria were diagnosis of T2DM by a specialist, no cognitive problems, ability to communicate in Persian, consent to participate in the study, being over 35 years old, and having at least one year of diagnosis of T2DM with active medical records. The exclusion criteria were dissatisfaction with completing the questionnaire and incomplete completion of the questionnaire.

\section{Assessment of illness perception \& medication adherence}

The data collection tool in this research is a questionnaire with three sections. The first section is related to personal characteristics, including age, gender, marital status, residence status, level of education, employment status, number of hospitalizations, duration of diagnosis, family history of diabetes, smoking, economic status, and smoking, which was completed based on the patient's statements and medical record. In the second section, The-Brief-Illness-Perception-Questionnaire (BIPQ) form was used to assess the illness perception. This questionnaire has 9 subscales that have been designed by Broadbent et al. based on the revised form of this questionnaire. The range of scores of the first 8 questions is from 1 to 10. Question 9 is open-answer and questions the three leading causes of the disease, respectively. Each subscale measures a component of illness perception. Five subscales measure cognitive response to disease, including the perception of outcomes, duration of illness, personal control, control through treatment, and symptom recognition. Two subscales measure worry about illness, emotions, and emotional response, and one subscale measures the illness perception ability. Cronbach's alpha for this questionnaire was as much as 0.8 . The reliability coefficient of the 6-week retest for different questions was reported from 0.42 to 0.75 [22]. In the third section, medication adherence was used using the 8-item MMAS-8 Drug Adherence Questionnaire developed by Morisky, Aang, and Wood et al. (2008). This questionnaire has 8 items. The method of scoring and interpreting this questionnaire is formulated only in item 8 on a 4-point Likert scale. Other items are answered by yes $=1$ and no = 0 . Items 5 and 8 are graded, unlike other items. The scores of all items in the questionnaire are 
summed to calculate the questionnaire's overall score. Its overall score range is between zero and 8. A score greater than 2 is poor drug adherence, 1 and 2 is moderate adherence, and 0 is considered as high adherence. In the research of Koushiar et al. (2013), while measuring the face and content validity of this tool by expert professors, its reliability was reported by Cronbach's alpha method as much as 0.68 [23].

\section{Assays}

This research has been approved by the ethics committee of Gonabad University of Medical Sciences under the No. IR.GMU.REC.1398.104. the researcher obtained the necessary permits to conduct the research with the director of Allameh Bohool Gonabadi Hospital's permission after being introduced to the research environment to comply with the ethical standards for conducting research. The researchers referred to the diabetes clinic of Allameh Bhlul Gonabadi Hospital to collect the data. The units were provided to patients to answer and ensure the confidentiality of information after stating the purpose of the study to the patient and obtaining consent and declaration of readiness. If the patient was illiterate, the questions were read to him/her by the researcher. Moreover, medical information was extracted from patients' records. First, the obtained data were initially examined.

\section{Statistical analysis}

The data were imported to SPSS20 software. Data were described using descriptive statistics, and then data analysis was performed. Chi-square test was used to compare the grouped data, Pearson correlation coefficient was used to determine the relationship, and Independent t-test and ANOVA were used to compare quantitative data in groups related to contextual variables. The significance level in the tests was considered as much as 0.05 .

\section{Results}

The present research was conducted on 260 patients with type II diabetes to determine the relationship between illness perception and medication adherence. The mean and standard deviation of patients' age was $59.05 \pm 11.55$, and 154 (59.23\%) were women. A total of 226 (86.92\%) participants were married, and 231 (91.54\%) were homeowners. A total of 134 (51.54\%) participants had less than a diploma. In terms of economic status, $71.53 \%$ were in the middle class, and in terms of employment, 53.46\% were housewives. In terms of smoking and drug addiction, $88.46 \%$ and $99.77 \%$, respectively, had no history of use. In terms of diet, $65.38 \%$ had a regular diet. In terms of medication, $65.38 \%$ took oral anti-diabetic medication (Table 1).

Regarding the illness perception, the results showed that the mean and standard deviation of the total score of illness perception in patients with type II diabetes was $45.9 \pm 39.46$ (range 0-70), and the duration of the disease was $7.97 \pm 2.67$.

The results showed that the mean and standard deviation of the medication adherence score was $1.69 \pm 2.93$ (range 0-8). According to the severity of medication adherence of type II diabetic patients, 154 patients (59.2\%) had poor drug adherence (Table 2).

According to the study of the relationship between gender with different dimensions of illness perception and medication adherence of type II diabetic patients, the results show a significant relationship between total scores of illness perception and gender $(\mathrm{P}<0.001)$, so that the rate of 
adherence in women was higher than men $(\mathrm{P}<0.001)$. There is a significant difference between the education of research units in terms of scores of dimensions of illness perception and also the total score of illness perception and medication adherence $(\mathrm{P}<0.05)$ Table $(3)$.

The correlation matrix was used to examine the relationship between illness perception and medication adherence. The results showed a significant relationship between illness perception and medication adherence in patients with type II diabetes $(r=0.199, \mathrm{P}=0.001)$. Among the components of illness perception, components of illness perception and personal control had a significant effect on medication adherence $(\mathrm{P}<0.001)$ (Table 4$)$. The results of examining the dimensions of illness perception and some studied variables on illness perception and medication adherence showed a significant relationship between FBS and $\mathrm{Hg}$ A1C with illness perception and age variables, FBS and $\mathrm{Hg} \mathrm{A} 1 \mathrm{C}$ with medication adherence $(\mathrm{P}=0.001)$ (Table 5).

Table 1. Frequency distribution and demographic characteristics of patients with type II diabetes

\begin{tabular}{|c|c|}
\hline \multirow[t]{2}{*}{ characteristics } & $\mathrm{N}(\%)$ \\
\hline & Mean $\pm S D$ \\
\hline \multicolumn{2}{|l|}{ Gender } \\
\hline Male & $106(40.77)$ \\
\hline Female & $154(59.23)$ \\
\hline \multicolumn{2}{|l|}{ Marital status } \\
\hline Single & $7(2.69)$ \\
\hline Married & $226(86.92)$ \\
\hline Widow & $8(30.8)$ \\
\hline Divorced & $19(7.31)$ \\
\hline \multicolumn{2}{|l|}{ education } \\
\hline High school & $198(76.15)$ \\
\hline Diploma & $34(13.08)$ \\
\hline University & $28(10.77)$ \\
\hline \multicolumn{2}{|c|}{ Economic status } \\
\hline Good & $14(5.39)$ \\
\hline Moderate & $186(71.53)$ \\
\hline
\end{tabular}




\begin{tabular}{lc}
\hline Weak & $60(23.08)$ \\
BMI & $26.47 \pm 4.27$ \\
HbA1C & $8.43 \pm 1.83$ \\
\hline
\end{tabular}

Table 2. Frequency distribution based on the severity of medication adherence of type II diabetic patients

\begin{tabular}{lcc}
\hline Variable & $\mathbf{N}$ & $\mathbf{\%}$ \\
\hline High adherence & 0 & 0 \\
Medium adherence & 106 & 40.8 \\
Poor adherence & 154 & 59.2 \\
Total & 260 & 100 \\
\hline
\end{tabular}

Table 3. The relationship between education and different dimensions of illness perception and medication adherence of type II diabetic patients

\begin{tabular}{lllllr}
\hline Education & \multicolumn{1}{l}{$\begin{array}{l}\text { High } \\
\text { School }\end{array}$} & Diploma & University & $\begin{array}{l}\text { ANOVA } \\
\text { result }\end{array}$ & test \\
& & & & & \\
\hline Perception of consequences & $8.03 \pm 2.58$ & $6.52 \pm 3.57$ & $5.18 \pm 3.70$ & $\mathrm{P}<0.001$ \\
Duration of the disease & $7.83 \pm 2.65$ & $8.45 \pm 2.39$ & $8.30 \pm 3.12$ & $\mathrm{P}=0.374$ \\
Personal control & $3.00 \pm 2.17$ & $2.88 \pm 2.58$ & $2.18 \pm 1.66$ & $\mathrm{P}=0.193$ \\
Control through treatment & $2.98 \pm 2.63$ & $3.44 \pm 2.73$ & $2.48 \pm 2.49$ & $\mathrm{P}=0.369$ \\
$\begin{array}{l}\text { Recognizing patients' } \\
\text { symptoms }\end{array}$ & $6.83 \pm 2.40$ & $5.61 \pm 2.88$ & $6.37 \pm 3.11$ & $\mathrm{P}=0.034$ \\
Worry about the disease & $7.92 \pm 2.49$ & $6.88 \pm 2.99$ & $7.00 \pm 3.66$ & $\mathrm{P}=0.045$ \\
Illness perception ability & $3.18 \pm 2.59$ & $2.41 \pm 2.54$ & $1.00 \pm 1.41$ & $\mathrm{P}<0.001$ \\
\hline
\end{tabular}




\begin{tabular}{|c|c|c|c|c|}
\hline $\begin{array}{l}\text { Emotions and emotional } \\
\text { reactions }\end{array}$ & $8.06 \pm 2.75$ & $5.85 \pm 3.71$ & $5.85 \pm 3.90$ & $\mathrm{P}<0.001$ \\
\hline \multirow[t]{2}{*}{ Total perception of illness } & 8.26 & 10.89 & $39.27 \pm 11.35$ & $\mathrm{P}<0.001$ \\
\hline & 48.03 & $42.27 \pm$ & & \\
\hline Total medication adherence & $3.07 \pm 1.77$ & $2.97 \pm 1.40$ & $2.88 \pm 1.42$ & $\mathrm{P}=0.834$ \\
\hline
\end{tabular}

Table 4. Correlation matrix between dimensions of illness perception and medication adherence

\begin{tabular}{lrr}
\hline Variable & Correlation coefficient (r) & Significance (P) \\
\hline Perception of consequences & 0.090 & 0.149 \\
Duration of the disease & -0.023 & 0.079 \\
Personal control & 0.179 & $* 0.004$ \\
Control through treatment & 0.064 & 0.305 \\
Recognizing patients' symptoms & 0.158 & $* 0.038$ \\
Worry about the disease & 0.020 & 0.751 \\
Illness perception ability & 0.252 & $* \mathrm{P}<0.001$ \\
Emotions and emotional reactions & 0.085 & 0.173 \\
Total & 0.189 & $* 0.002$ \\
\hline
\end{tabular}

Table 5. Correlation matrix between some demographic variables with illness perception and medication adherence of type II diabetic patients

\begin{tabular}{lcccc}
\hline Variable & \multicolumn{2}{c}{ Illness perception } & \multicolumn{2}{c}{ Medication adherence } \\
& $\begin{array}{c}\text { Correlation } \\
\text { coefficient } \\
(\mathbf{r})\end{array}$ & $\begin{array}{c}\text { Significance } \\
(\mathbf{P})\end{array}$ & $\begin{array}{c}\text { Correlation } \\
\text { coefficient } \\
(\mathbf{r})\end{array}$ & $\begin{array}{c}\text { Significance } \\
(\mathbf{P})\end{array}$ \\
\hline Age & 0.166 & $* 0.008$ & 0.137 & $* 0.029$ \\
$\begin{array}{l}\text { Duration of } \\
\text { diabetes }\end{array}$ & 0.151 & $* 0.042$ & 0.059 & 0.344 \\
$\begin{array}{l}\text { Number of } \\
\text { hospitalizations }\end{array}$ & 0.134 & 0.082 & -0.047 & 0.541 \\
\hline
\end{tabular}




\begin{tabular}{lcccc}
\hline FBS & -0.173 & $* 0.006$ & -0.153 & $* 0.043$ \\
Hg A1C & -0.288 & $* \mathrm{P}<0.001$ & -0.191 & $* 0.005$ \\
BMI & -0.050 & 0.465 & -0.078 & 0.187 \\
\hline
\end{tabular}

\section{Discussion}

The purpose of this research was to investigate the relationship between illness perception and medication adherence. The results indicated relatively low medication adherence, which is not consistent with Dost Mohammadi et al., Who reported high medication adherence in the elderly with hypertension [20]. It can be explained that patients with hypertension possibly were more aware of the disease and its risks.

The illness perception results in patients with Type II Diabetes participating in the research showed that more than half of the patients report their illness perception as moderate and above. These results are consistent with Dost Mohammadi et al. [21] and Angell et al. entitled "Measurement Strategies" used by mental health providers to encourage them to follow medication [22]. Furthermore, this research is consistent with the findings of Christensen entitled "Psychological aspects of end-stage renal disease" and Taherkhani et al. entitled "The relationship between illness perception and medication adherence in patients with hypertension [23, 24].

Various protective mechanisms have been proposed to explain the effects of illness perception on medication adherence. Most of these mechanisms are summarized in two areas, which are physical factors and psychological mediators. The factor that has received the most experimental support concerning physical factors is the lower activity of the hypothalamic-pituitary-adrenal axis in people who have a rational perception of illness and believe in appropriate treatment [25]. Regarding psychological mediators that mediate the illness perception with medication adherence, medication adherence can affect psychological factors. On the other hand, these factors affect medication adherence. Mohammadpour et al., in a study entitled "Investigation of patient's educational needs in the discharge phase in health centers," showed that lack of awareness about the illness is one of the factors correlated to medication non-adherence [26].

The two components of personal control and illness perception ability in the illness perception group had a significant relationship in medication adherence in patients with type II diabetes, which means that those who have a greater perception of their illness, their health status is subject to their personal control, feel more responsible for their health, and follow higher treatment. The results of this research are in line with the previous studies on illness perception level and their medication adherence [27, 28, 29]. Rajpura and Nayak, in a study entitled “

Evaluation of the effect of illness perception, therapeutic beliefs, illness burden, and medication adherence in the elderly with hypertension" reported a positive relationship between illness perception and positive beliefs about treatment in the elderly with hypertension with high medication adherence [28]. Taheri Kharameh et al. conducted a study entitled "The relationship between illness perception and medication adherence in patients with hypertension." They 
concluded that the two components of personal control and illness perception ability were the most important predictors of medication adherence, consistent with this research [30]. Ross et al., in a study entitled "The role of illness perception and therapeutic beliefs in patient adaptation to hypertension," concluded that illness perception and beliefs about hypertension predict patient adherence [27]. Kang et al., in a study entitled "Source of control and adherence to antihypertensive drugs in Ghana," showed that patients with better perceived health status were more likely to adhere to medication [31]. The results of research on the relationship between illness perception and medication adherence can be described according to cognitive theories. Cognitive theories and models assume that the individuals' perceptual characteristics and organization lead to the formation of some characteristics such as being sensitive, being emotional, low-risk perception, and not paying attention to negative consequences. These characteristics lead to weakness in problem-solving, insufficient emotional processing, irritability, as well as the development of specific behavioral characteristics that impair adherence to personal care instructions and, to a more specific level, medication adherence [32]. When there is no proper perception of the illness consequences, people are less likely to follow health care behaviors. Therefore, they ignore the medical instructions of the therapist to obtain temporary and momentary pleasures and desires. In other words, people ignore the treatment instructions due to the low-risk perception of the illness. In other words, people disobey their physician's treatment instructions due to the low-risk illness perception and use behaviors opposed to their medication as a useful means to achieve their desires [33].

\section{Conclusions}

In conclusion, we found that low medication adherence is predictable when the illness perception is low. There is a significant relationship between illness perception and medication adherence in patients with type II diabetes. Strengthening illness perception to increase patient's medication adherence is a critical treatment strategy in educational interventions. Therefore, it is recommended to evaluate the relationship between spiritual health and illness perception of diabetic patients. One of the limitations of this study is that the present research tests are selfassessment tests. The measured abilities and characteristics in this self-assessment are based on individuals' self-perception, which is closely related to their self-concept. If self-concept does not correspond to reality, such scales cannot well reflect the individual's true characteristics and abilities and only express the individual's self-perception.

\section{Abbreviations}

T2DM: Type 2 diabetes mellitus; NIH: National institutes of health; WHO: World health organization; BIPQ: The-Brief Illness Perception Questionnaire; MMAS-8: Medication Adherence Scale Morisky

\section{Acknowledgements}


The authors of this research would like to express their appreciation to the Clinical Research Development Unit of Allameh Bohlool Gonabadi Teaching and Research Hospital and Gonabad University of Medical Sciences, and all the participants in the research.

\section{Authors' contributions}

SSB and ADN designed the study, SSB and HA were involved in collecting the data and patients management, ADN performed the data analysis. SSB drafted the manuscript. All authors read and approved the final manuscript.

\section{Funding}

The study is supported by Gonabad University of Medical Sciences.

\section{Availability of data and materials}

The datasets used and/or analyzed during the current study are available from the corresponding author upon reasonable request.

\section{Declarations}

\section{Ethics approval and consent to participate}

All subjects were informed of the study aims and provided written consent before entering the study, which was conducted in accordance with the Declaration of Helsinki and approved by the This research is the result of a research project approved by the ethics committee with number IR.GMU.REC.1398.104 of Gonabad University of Medical Sciences, Iran.

\section{Consent for publication.}

Not applicable.

\section{Competing interests}

The authors declare that they have no competing interest.

\section{Author details}

${ }^{1}$ Bsc in Nursing, Islamic Azad University of Gonabad, Gonabad, Iran ${ }^{2}$ Assitant Professor, PhD in Health Psychology, Social Development and Health Promotion Research Center, Gonabad University of Medical Sciences, Gonabad, Iran ${ }^{3}$ Msc in Intensive Care Nursing, Clinical Reasearch Development Unit, Gonabad University of Medical Sciences, Gonabad, Iran

\section{References}

1. Shamsi M, Tajik R, Mohammad Beigi A. Effect of education based on Health Belief Model on self-medication in mothers refering to health centers of Arak. Arak Medical University Journal (Rahavard Danesh) 2009;12(3): 44-53

2. Samini M, Shafarood H, Sehat V, Allahdini S. Self-therapy and culture of drug use. Razi Drug Journal 2005; 9(1): 37-47. 
3. Shamsi M, Bayati A. A survey of the Prevalence of Self-medication and the Factors Affecting it in Pregnant Mothers Referring to Health Centers in Arak city, 2009. Journal of Jahrom Medical School 2010; 7(3): 34-41.

4. World Health Organization. The world drug situation, Geneva: World Health Organization 1988; 110-120. 8Dormandy JA, Charbonnel B, Eckland DJ, Erdmann E, Massi-Benedetti M, Moules IK 1et al. Secondary prevention of macrovascular events in patients with type 2 diabetes in the PROactive Study (PROspective pioglitAzone Clinical Trial In macroVascular Events): a randomised controlled trial. The Lancet. 2005;366(9493):127989

5. Maddah M. Association of Parental Diabetes with Overweight in Iranian Children and Adolescents. International Journal of Cardiology. 2008; 12(5): 1-3. [Persian].

6. Shabani A. Review in system drug in Iran. Razi Drug Journal 2003; 5: 60-62.

7. Ziayee T. The survey of self-medication in woman with pregnancy in Tehran. Scientific journal of university nurse and midwife shahid beheshty 2008; 8(2): 35-42.

8. Sepehri GH, HajAkbari N, Musavi A. Study indexes of general practitioners prescriptions in Kerman province 2003. Journal of Babol University of Medical Science 2005; 7(4): 7682.

9. Sawalha AF. A descriptive study of self- medication practices among Palestinian medical and nonmedical university students. Research in Social Adminastrative Pharm 2008; 4(2): $164-172$

10. Shojaiizadeh D. Health behavior models. Edi 1, Tehran, Publisher Chehr 2009; 20-29.

11. Hill CJ, Cardwell CR, Patterson CC, Maxwell AP, Magee GM, Young RJ, et al. Chronic Kidney Disease and Diabetes in the National Health Service: A Cross-sectional Survey of the U.K, National Diabetes Audit. Diabet Med. 2014; 31(4): 448-54.

12. Sabaté E. Adherence to long-term therapies: evidence for action: World Health Organization; 20033

13. Takemura M, Mitsui K, Itotani R, Ishitoko M, Suzuki S, Matsumoto M, et al. Relationships between repeated instruction on inhalation therapy, medication adherence, and health status in chronic obstructive pulmonary disease. Int $\mathrm{J}$ Chron Obstruct Pulmon Dis. 2011;6:97-104

14. Abbasi M, Salemi S, Fatemi N, Hosseini F. [Hypertensive patients, their compliance level and its' relation to their health beliefs]. Iran J Nurs. 2005; 18(41):61-8.

15. Leventhal H, Meyer D, Nerenz D. The common sense representation of illness danger. In: Rachman S, editor. Medical psychology. New York: Pergamon Press; 1980. p. 7-30.

16. Broadbent E, Petrie KJ, Main J, Weinman J. The brief illness per- ception questionnaire. J Psychosom Res. 2006; 60(6):631-7. DOI: 10.1016/j.jpsychores.2005.10.020 PMID: 16731240

17. Rajpura J, Nayak R. Medication adherence in a sample of elderly suffering from hypertension: evaluating the influence of illness perceptions, treat- ment beliefs, and illness burden. J Manag Care Pharm. 2014; 20(1):58-65. DOI: 10.18553/jmcp.2014.20.1.58 PMID: 24511766

18. Chen SL, Tsai JC, Lee WL. The impact of illness perception on ad- herence to therapeutic regimens of patients with hypertension in Taiwan. J Clin Nurs. 2009; 18(15):2234-44. DOI: 10.1111/j.1365- 2702.2008.02706.x PMID: 19583655 
19. Chen SL, Tsai JC, Chou KR. Illness perceptions and adherence to therapeutic regimens among patients with hypertension: a structur- al modeling approach. Int J Nurs Stud. 2011; 48(2):235-45. DOI: 10.1016/j.ijnurstu.2010.07.005 PMID: 20678768

20. Doust Mohammadi S, Norouzi K, Dalvandi A, Norouzi M. The Level of Illness Perception and its Relationship with Adherence to the Medical Regimen in the Elderly with Hypertension. IJRN. 2018; 4 (3):40-46(Persian).

21. Broadbent E, Petrie KJ, Main J, Weinman J. The brief illness per- ception questionnaire. J Psychosom Res. 2006; 60(6):631-7. DOI: 10.1016/j.jpsychores.2005.10.020 PMID: 16731240

22. Shoorvazi.M, Kooshyar.H, Dalir.Z, Hosseini.M. Health Literacy and its Relationship with Medical Adherence and Health-Related Quality of Life in Diabetic CommunityResiding Elderly. J Mazand Univ Med Sci 2014; 24(Supple 1): 134-143 (Persian).

23. Angell B. Measuring strategies used by mental health providers to encourage medication adherence. J Behav Health Serv Res. 2006; 33(1):53-72. DOI: 10.1007/ s11414-005-90004 PMID: 16636908

24. Taheri-Kharameh Z, Hazavehei S M M, Ramezani T, Vahedi A, Khoshro M, Sharififard F. The Assessment of Illness Perception and Adherence to Therapeutic Regimens among Patients with Hypertension. J Educ Community Health. 2016; 3 (2) :915URL: http://jech.umsha.ac.ir/article-1-219-fa.html

25. Christensen AJ, Moran PJ. Psychological aspects ofend-stage renal disease. In: Bellack A, editor. Comprehensive Clinical Psychology. New York: Pergamon; 2008. p. 321-38.

26. Soundy A, Muhamed A, Stubbs B, Probst M, Vancampfort D. The benefits of walking for individuals with schizophrenia spectrum disorders: A systematic review. Int J Ther Rehabil. 2014; 21(9):410-20. DOI: 10.12968/ijtr.2014.21.9.410

27. Mohammad Pour A, Dehgan Naieri N. The survey of the patient educational need on discharge phase in Gonabad health and treatment centers. Horiz Med Sci. 2007; 12(4):349.

28. Ross S, Walker A, MacLeod MJ. Patient compliance in hyperten- sion: role of illness perceptions and treatment beliefs. J Hum Hy- pertens. 2004; 18(9):607-13. DOI: 10.1038/sj.jhh.1001721 PMID: 15029218

29. Rajpura J, Nayak R. Medication adherence in a sample of elderly suffering from hypertension: evaluating the influence of illness perceptions, treat- ment beliefs, and illness burden. J Manag Care Pharm. 2014; 20(1):58-65. DOI:10.18553/jmcp.2014.20.1.58 PMID: 24511766 
30. Taheri-Kharameh Z, Hazavehei S M M, Ramezani T, Vahedi A, Khoshro M, Sharififard F. The Assessment of Illness Perception and Adherence to Therapeutic Regimens among Patients with Hypertension. J Educ Community Health. 2016; 3 (2) :9-15 URL: http://jech.umsha.ac.ir/article-1-219-fa.html

31. Kretchy IA, Owusu-Daaku FT, Danquah S. Locus of control and anti-hypertensive medication adherence in Ghana. Pan Afr Med J. 2014; 17 suppl 1:13. DOI: 10.11694/pamj.supp.2014.17.1.3433 PMID: 24624246

32. Payne J, Bettman J, Luce M. Behavioral decision making research: An overview. Meas Jung Dec Making. 2010; 30:1-45.

33. Johnson SL, Turner RJ, Iwata N. BIS / BAS levels and psychiatric disorder: An epidemiological study. J Psychopathol Behav Assess. 2003; 25(1):25-36. DOI: 10.1023/a:1022247919288 